\title{
Beta-blockers after myocardial infarction: Are they useful to all patients? And how long should be the beta-blocker therapy?
}

\author{
Roberto F.E. Pedretti \\ Department of Cardiac Rehabilitation, Istituti Cinici Scientifici Maugeri IRCCS, Pavia, Italy
}

\begin{abstract}
Some observational studies raised questions about the need for $\beta$-blockers in all patients after a first heart attack. Surprisingly, in some clinical settings, a limited mortality reduction was found in those who received $\beta$-blockade.

Some studies suggest that patients without heart failure may not need post-infarction $\beta$-blockers. The lack of data from randomized controlled clinical trials has led to clinical uncertainty and conflicting recommendations. Therefore, there are multiple information to revaluate the value of $\beta$-blocker therapy after a heart attack in absence of heart failure or left ventricular dysfunction and the time for new trials of an old group of drugs has arrived.
\end{abstract}

According the results of two randomized controlled trials, the $\beta$-Blocker Heart Attack Trial (BHAT) and the Norwegian Multicenter Study Group trial, $\beta$-blockers received the indication for patients recovering from myocardial infarction [1,2].

A review from Freemantle et al. confirmed the beneficial effects of $\beta$-blockers. The study included 31 long-term randomized controlled trials and showed a $23 \%$ reduction in the odds of death for patients with $\beta$-blockers compared with those without after a heart attack [3].

Based on these data, guidelines [4] stated that all patients after a heart attack should be prescribed a $\beta$-Blocker for secondary prevention for a time of three years in absence of contraindications. Nevertheless, in the subsequent years the optimal medical therapy after a heart attack has acquired several other drugs in order to make secondary prevention interventions after myocardial infarction more effective: statins, angiotensin-converting enzyme inhibitors, and antiplatelet or

Corresponding author: Roberto F.E. Pedretti, Istituti Clinici Scientifici Maugeri IRCCS, Via Maugeri 4, 27100 Pavia, Italy. Tel. +39.0382.592883. E-mail: roberto.pedretti@icsmaugeri.it

Received for publication: 27 May 2018

Accepted for publication: 28 May 2018

(C) Copyright R.F.E. Pedretti, 2018

Tipografia PI-ME Editrice, Italy

Monaldi Archives for Chest Disease 2018; 88:971

doi: 10.4081/monaldi.2018.971

This article is distributed under the terms of the Creative Commons Attribution Noncommercial License (by-nc 4.0) which permits any noncommercial use, distribution, and reproduction in any medium, provided the original author(s) and source are credited. anticoagulants. Moreover, patients commonly undergo reperfusion therapy during the acute phase of myocardial infarction as well as during the chronic phase if residual ischemia is present despite medical therapy. Based on this new therapeutic scenario it may be reasonable to ask if $\beta$-blockers are still needed in all post-infarction patients, because adherence to recommended therapies is often poor and every patient chooses which of the prescribed prophylactic medications take after a heart attack.

Korhonen et al. studied more than 90,000 medicare patients who were hospitalized for an acute myocardial infarction between 2008 and 2010 with a survival of at least 6 months [5]. According to guidelines, they were prescribed with $\beta$-blockers, angiotensin-converting enzyme inhibitors or angiotensin II receptor blockers and statins. The study showed that approximately $50 \%$ of patients had adherence to all the three categories of drugs [5]. More interestingly, at a follow-up of 18 months, those patients who interrupted $\beta$-blockers but were still in treatment with statins and angiotensin-converting enzyme inhibitors or angiotensin II receptor blockers had a similar mortality to those treated with all 3 drugs [5]. Finally, patients who took $\beta$-blockers with only 1 of the other therapies [statins or angiotensin-converting enzyme inhibitors or angiotensin II receptor blockers] had higher mortality rates than those who fully adhered to all 3 drugs [5]. These findings were in clear contrast with previous evidence showing a substantial neutral effect of $\beta$-blockers on prognosis after a heart attack and a subordinate position of $\beta$-blockers in comparison to statins and angiotensin-converting enzyme inhibitors or angiotensin II receptors in the secondary prevention pharmacopoeia. Therefore, the authors suggest that $\beta$-blockers may not be needed if statins and angiotensin-converting enzyme inhibitors or angiotensin II receptors are assumed by the patients, in particular when other indications, such as heart failure or arrhythmia, are not present.

Supporting the hypothesis that $\beta$-blockers may not now considered "routine" drugs after a myocardial infarction is another finding of the study which showed that patients with diabetes or dementia had a higher mortality risk if they only took $\beta$-blockers [5].

Controlled trials are needed to better support these findings because it may be possible that without the confounding factors of observational studies, $\beta$-blockers may be still effective in every patient. Nevertheless, it is possible that patients who after a myocardial infarction still have a good left ventricular function and arewithout heart failure or residual ischemia may not necessarily need long-term therapy with $\beta$-blockers.

In fact, the BHAT, a multicentre placebo-controlled randomized trial, demonstrated a $30 \%$ reduction in mortality with $\beta$-blockers, however the largest benefit in survival was in people with heart failure [1] and the benefit of $\beta$-blockers in people with heart failure, with reduction in both mortality and rehospitalizations, is not under discussion.

On the other hand, $\beta$-blockers have not been evaluated in a large trial enrolling patient with a heart attack without heart failure and treated with the other drugs useful in the secondary prevention, such as statins and angiotensin-converting enzyme inhibitors or angiotensin II receptors. 
The lack of data from randomized controlled clinical trials has led to clinical uncertainty and conflicting recommendations. Unlike the US guidelines, European guidelines don't recommend $\beta$-blockers as a firstline prophylactic therapy for all patients [6].

Some studies suggest that patients without heart failure may not need post-MI $\beta$-blockers. A 2015 meta-analysis including almost 41000 patients who underwent percutaneous coronary intervention after myocardial infarction showed that $\beta$-blockers were associated with a reduced risk of death only in specific subgroups of patients, including those with reduced ejection fraction, heart failure or low use of other prophylactic drugs [7].

In an observational cohort study including almost 180,000 patients Dondo et al. found no survival benefit of $\beta$-blockers at any time point up to 1 year after hospitalization for patients who had a heart attack but did not have heart failure or left ventricular dysfunction [8].

In a 2016 cohort study enrolling almost 2700 patients with heart attack without heart failure or left ventricular dysfunction, $\beta$-blocker use was associated with a lower 30-day mortality but not a lower 5-year mortality, suggesting that long-term use may not save lives [9].

Therefore, there are multiple information to revaluate the value of $\beta$-blocker therapy after a heart attack in absence of heart failure or left ventricular dysfunction and the time for new trials of an old group of drugs has arrived. As underlined before, the contemporary treatment is different and also the post-infarction population is deeply changed including old and very old patients in a significant high proportion. Nevertheless, as usual, women were also underrepresented in early trials. Finally, the extensive use of enzyme-based diagnostics, has changed the definition of myocardial infarction and more patients with small infarction are now considered in daily clinical practice.

A Sweden's national cardiac registry could give a very important contribution to the field. In the REDUCE-SWEDEHEART trial, 7000 patients with a normal left ventricular ejection fraction are randomized 1-7 days after myocardial infarction to either long-term $\beta$-blockers or no $\beta$-blockers. The end-point will be to determine if $\beta$-blockers may reduce re-infarctions and all-cause death over a long-term follow-up.

\section{References}

1. [No authors listed]. A randomized trial of propranolol in patients with acute myocardial infarction. I. Mortality results. JAMA 1982;247:1707-14.

2. Norwegian Multicenter Study Group. Timolol-induced reduction in mortality and reinfarction in patients surviving acute myocardial infarction. N Engl J Med 1981;304:801-7.

3. Freemantle N, Cleland J, Young P, Mason J, Harrison J. Beta blockade after myocardial infarction: systematic review and meta regression analysis. BMJ 1999;318:1730-7.

4. Smith SC Jr, Benjamin EJ, Bonow R0, et al. AHA/ACCF secondary prevention and risk reduction therapy for patients with coronary and other atherosclerotic vascular disease: 2011 update: a guideline from the American Heart Association and American College of Cardiology Foundation. J Am Coll Cardiol 2011;58:2432-46.

5. Korhonen MJ, Robinson JG, Annis IE, et al. Adherence tradeoff to multiple preventive therapies and all-cause mortality after acute myocardial infarction. J Am Coll Cardiol 2017;70:1543-154.

6. Roffi M, Patrono C, Collet J-P, et al. 2015 ESC Guidelines for the management of acute coronary syndromes in patients presenting without persistent ST-segment elevation: Task Force for the Management of Acute Coronary Syndromes in Patients Presenting without Persistent ST-Segment Elevation of the European Society of Cardiology (ESC). Eur Heart J 2016;3:267-315.

7. Huang BT, Huang FY, Zuo ZL, et al. Meta-analysis of relation between oral $\beta$-blocker therapy and outcomes in patients with acute myocardial infarction who underwent percutaneous coronary intervention. Am J Cardiol 2015;115:1529-38.

8. Dondo TB, Hall M, West RM, et al. $\beta$-Blockers and mortality after acute myocardial infarction in patients without heart failure or ventricular dysfunction. J Am Coll Cardiol 2017;69:2710-20.

9. Puymirat E, Riant E, Aissaoui N, et al. $\beta$ blockers and mortality after myocardial infarction in patients without heart failure: multicentre prospective cohort study. BMJ 2016;355:i5602. 